\author{
Justyna Kobus \\ Uniwersytet im. Adama Mickiewicza w Poznaniu \\ Instytut Filologii Polskiej Poznań \\ ORCID: 0000-0002-4094-2743; e-mail: jusper@amu.edu.pl
}

\title{
Formy miejscownika liczby pojedynczej wyrazu dom w mowie Wielkopolan dawniej i współcześnie
}

\begin{abstract}
Abstrakt: Artykuł poświęcony jest zagadnieniu zróżnicowania form fleksyjnych miejscownika wyrazu dom. Materiałem wyjściowym uczyniono Atlas języka i kultury ludowej Wielkopolski (materiał dziś już dawny), z którym zestawione zostały wyniki badań współczesnych. Zabieg ten pozwolił wykazać stopień żywotności form gwarowych we współczesnym języku mieszkańców wsi, szczególnie zaś regresywny charakter opisywanych przykładów.
\end{abstract}

Słowa kluczowe: gwara, język mieszkańców wsi, miejscownik, dom.

Abstract: Forms of the singular locative of the word dom in the speech of inhabitant of Greater Poland in the past and today. The article is devoted to the issue of the diversity of the inflectional forms of the locative expression of the word dom (the house). The starting material was the Atlas of the regional language and folk culture of Greater Poland (today considered obsolete) against which the results of contemporary research were compared. This procedure allowed to show the vitality of dialectal forms in the modern language of villagers, especially the regressive nature of the described examples.

Keywords: dialect, language of villagers, locative, house.

Różnorodność form fleksyjnych wyrazu dom notowana jest w słownikach dokumentujących stan języka od czasów prasłowiańskich. Śledząc odmianę tego wyrazu odnajdziemy kilka form miejscownika w liczbie pojedynczej, które dość długo utrzymały się w gwarach. W artykule tym prześledzę losy form miejscownika wyrazu dom W gwarach wielkopolskich. W tym celu zestawię materiały archiwalne (z lat 70. i 80. XX w.) z pozyskanymi współcześnie w terenie (nagrania po 2000 r.). Wprawdzie metody badawcze dawne i współczesne znacznie się różnią, jednakże dla stwierdzenia żywotności nierzadkiej jednostki leksykalnej nie będą one skonfliktowane¹.

Niewiele jest literatury przedmiotu uwzględniającej różnorodność form miejscownika wyrazu dom (w ogóle literatura dotycząca fleksji, szczególnie gwarowej, nie jest

\footnotetext{
${ }^{1}$ Metodologia zespołu badającego mowę ludności wiejskiej dla potrzeb Atlasu języka i kultury ludowej Wielkopolski jest zupełnie różna od metod stosowanych współcześnie przez zespół Pracowni Dialektologicznej UAM, który nastawiony jest na pozyskiwanie tekstów ciągłych dla potrzeb badania słownictwa gwarowego z myślą o słowniku tego regionu. Zróżnicowane podejścia badawcze implikują m.in. inną gęstość siatki punktów badawczych dawniej i dziś, sposób pozyskiwania poświadczeń itd.
} 
zbyt bogata). Zwykle formy te wymieniane są jako przykłady tegoż przypadka z archaiczną końcówką - $u$, która weszła do systemu jako końcówka fleksyjna ogólna miejscownika tegoż rzeczownika. Mamy zatem do dyspozycji słowniki i atlasy gwarowe oraz ewentualnie monografie z różnych regionów, np. w Dialekcie malborskim Hubert Górnowicz tłumaczy pochodzenie formy $w$ dómu (Górnowicz 1967, 154), a Jan Tokarski w Gwarze Serpelic. Fonetyka. Fleksja jedynie wymienia wśród innych przykładów występującą tam formę domı (Tokarski 1964, 97).

Dokładnych analiz konkretnych przykładów należy szukać w atlasach regionalnych lub artykułach poświęconych danemu zagadnieniu fleksyjnemu. Formy 'w domu' były przedmiotem zainteresowania twórców Atlasu językowego polskiego Podkarpacia (Małecki, Nitsch 1934, m. 38) - poświadczono tu formy: doma, wdoma (!), w domu obok $w$ chałupie $^{2}$. Interesujący opis zróżnicowania form fleksyjnych wyrazu dom na pograniczu wielkopolsko-śląsko-małopolskim w województwie kaliskim dała Honorata Skoczylas-Stawska w artykule z 1999 r. (Skoczylas-Stawska 1999, 166-176). Najnowszym opracowaniem dotyczącym lokatiwu liczby pojedynczej od rzeczownika dom jest artykuł Haliny Karaś Formy oboczne miejscownika liczby pojedynczej (w) domu - (w) domie $w$ gwarach polskich na Litwie (Karaś 2018, 79-97).

Najbardziej wnikliwą analizę interesujących nas form miejscownika w gwarach wielkopolskich znajdziemy w Atlasie jezyka i kultury ludowej Wielkopolski (AJKLWVIII, m. 672.: Odpowiedniki fleksyjne ogpol. $w$ domu). W komentarzu do mapy 672. czytamy: „Wyraz dom, jak wiadomo, jest jednym z nielicznej grupy prasłowiańskich rzeczowników o tematach na ${ }^{*}-u$, które w miejscowniku 1 . poj. przybierały im tylko właściwą końcówkę - $u$. Tę tradycyjną końcówkę w dzisiejszym języku ogólnopolskim zachowały tylko trzy spośród pierwotnych rzeczowników z tematem na *-u - właśnie dom oraz syn, wierzch: w domu, o synu i na wierzchu" (KomAJKLW-VIII, 56).

$\mathrm{Z}$ komentarza dowiemy się także, że na całym niemal obszarze notowano ogólnopolską formę $w$ domu, która niekiedy była wyłączną na danym terenie, obok form o starszej proweniencji, które wykazywały zasięg ograniczony do pewnych konkretnych miejsc.

Zespół AJKLW pozyskał poświadczenia dla form: $w$ domie, $w$ domu, doma, $w$ do$m a$. Dla każdej z tych form przywołany jest rodowód historycznojęzykowy, który jako fakt interesujący i uzupełniający niniejszy wywód - każdorazowo przytoczę.

Materiał współczesny będę opisywać na podstawie wybranych wsi, które są reprezentantami poszczególnych podregionów Wielkopolski. W miejscowościach tych pozyskany został materiał od informatorów na tyle zróżnicowanych pokoleniowo, że nadaje się on do rozmaitych analiz, w tym do badania żywotności typowych dla gwar form fleksyjnych.

Nadmienię, że będę posługiwać się nazwami dialektalnych podregionów Wielkopolski w następujący sposób: Wielkopolska południowa - Bukówiec Górny, gm. Włoszakowice, pow. Leszno (będący zarazem 74 punktem badawczym AJKLW), Wielkopolska zachodnia - Dąbrówka Wielkopolska, gm. Zbąszynek, pow. Świebodzin (będąca zarazem 45 punktem badawczym AJKLW), Wielkopolska środkowa - Baranówko

\footnotetext{
${ }^{2}$ Nie zachowuję oryginalnego zapisu fonetycznego ze względów praktycznych.
} 
i Sowinki, gm. Mosina, pow. Poznań, Wielkopolska wschodnia - Adamów, gm. Golina, pow. Konin.

Już na wstępie chcę zaznaczyć, że nieodnotowanie poświadczenia dla poszukiwanej w materiałach współczesnych formy nie przesądza o jej całkowitym braku w mowie mieszkańców danej okolicy; dowodzi natomiast silnego jej regresu oraz najwyraźniej braku w języku badanych informatorów.

Przejdę zatem do charakterystyki materiału (zob. ryc. 1).

Forma $w$ domie: „stanowi (...) formalnie wyrażenie przyimkowe, w którym rzeczownik dom występuje $\mathrm{w}$ miejscowniku 1. poj. $\mathrm{z}$ wtórną $\mathrm{w}$ dawnych tematach na ${ }^{*}-u$ końcówką - 'e, przeniesioną z pierwotnych tematów na *-o (np. las : w lesi-e). Końcówka ta w rzeczowniku dom, szerząca się kosztem pierwotnej końcówki - $u$, poświadczona jest już w zabytkach staropolskich (SStp II 124). (...) Nasza mapa wykazuje konstrukcję $w$ domie 'w domu' przede wszystkim w gwarach południowej części badanego obszaru, rzadziej na północy" (KomAJKLW-VIII, 56) ${ }^{3}$. Formę tę notuje także Stownik gwar polskich PAN (SGP) na Orawie.

Współcześnie forma $w$ domie została poświadczona w Bukówcu Górnym (informatorzy: SbW - kobieta ur. 1917 r. nagranie z 9.04.2001 r., SoW - kobieta ur. 1920 r., nagranie z 1.02.2003 r; DoS - mężczyzna ur. 1921 r., nagranie z 8.01.2001 r.; S1J kobieta ur. 1923 r., nagranie z 24.04.2004 r. i 18.05.2004 r.; SzJ - mężczyzna ur. 1925 r., nagranie z 1.02.2006 r. i 3.02.2006 r., SoA - kobieta ur. 1928 r., nagranie z 3.02.2003 r. i 5.03.2003 r.; PoW - ur. 1928 r., nagranie z 20.05.2007 r. i 7.08.2008 r.; PoC - ur. 1942 r., nagranie z 30.01.2006 r.).

SbW: takie zielazne takie... my jeszcze może dzie mómy te dusze... zielozko... w starym dómie eszcze buło... to sie ugrzoło $i$ sie włożyło tak...

SbW: jak piece kachlane to tyż sie musiało wymiatadź nieraz... my w starym dómie mieli... taki piec...

SoW: uиu... kararepa... kapusta... marchew... pietruszka... nó i selera... takie coś... to wszysko jes przy dómie...

Najczęściej to $\mathrm{z}$ jakich desek robili?

DoS: to przeważnie sosnowe byty wtedy... tego... deski ze sosny... my mieli jeszcze w tym starym domie... to my mieli też...

Jak się nazywa przy budowie domu, kiedy na końcu takie coś przyczepiają...?

DoS: na dómie?...

S1J: ja miaa wtydy dziecko małe... win ${ }^{n} d z$ jachaa (!) teściowa z menżym... nie... i przy jeje (!) dómie... dzie tam mieszkała... tyn cały korowód szed... to jes nie do opowiedzynió...

PoW: teraz pan wie... nawet buła na tym... na jej dómie wypisane takimi dużymi literami hotel...

PoW: jez jedna wioska... ale czasym $\boldsymbol{w}$ każdym dómie tyż to używajóm inaczyj... nie...

\footnotetext{
${ }^{3}$ Formę $w$ dómie $\mathrm{w}$ znaczeniu 'w domu' zanotował już przed wojną Adam Tomaszewski w okolicach Drawska (współcześnie pow. Czarnków).
} 


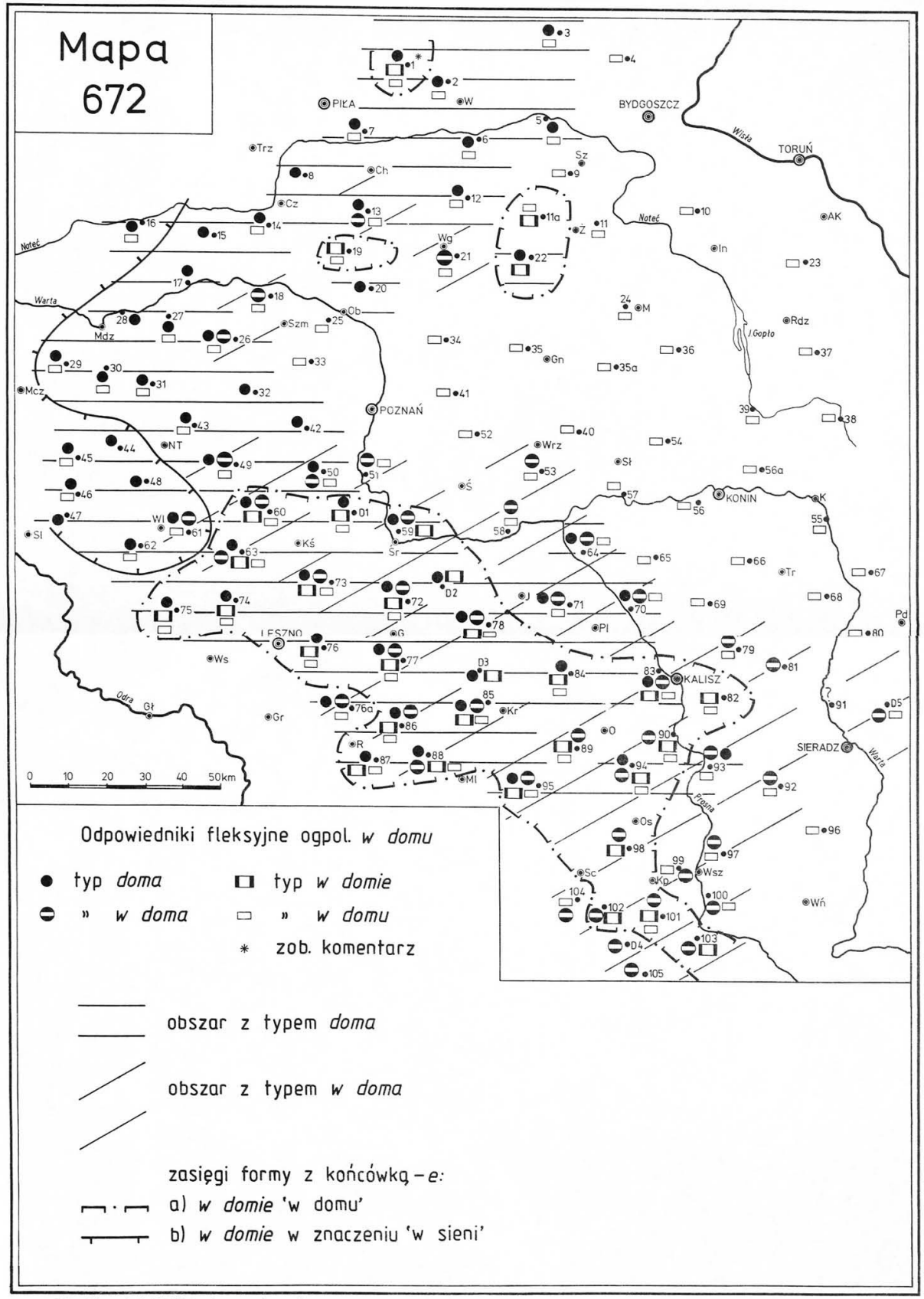

Mapa 672. Odpowiedniki fleksyjne ogpol. $w$ domu Oprac. H. Nowak

Ryc. 1. Mapa 672. Odpowiedniki fleksyjne ogpol. $w$ domu Źródło: AJKLW-VIII, Atlas języka i kultury ludowej Wielkopolski, red. Z. Sobierajski, cz. 1, Poznań 1994. 
SlJ: żeby to przyszed do przytomności... bo jag omdleje tyż celo ${ }^{m}$... nie.... zimnóm

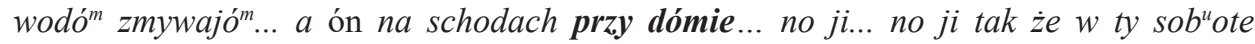
jeszczy przed tóm kómunióm $^{m}$ go poch ${ }^{u}$ owali...

SoA: przeciż nazwiska sie zminiajo ${ }^{m}$... nie... przecież tu jes... jak tu my mieszkómy w tym dómie na przykod... najpierw... bo my kupili... bo tu buło kupione... ale najpierw but Dekier...

Czy dziś jeszcze używa się sierpów?

SoA: tak przy dómie... jak tam ścióńdź jakimś tam trawe gdzieś tam... to tak...

SzJ: potem żeśmy tam do mieszkania tam dotarli... a myśmy spali $\boldsymbol{w}$ takim domie co nam bomba $w$ pobliżu gdzieś tam spadła...

Ale dzisiaj to trochę chłodno jeszcze.

SzJ: ale człowieka już ciongnie... bo już w dómie tu siedziedź $i$ (...?) dejcie spokój...

SzJ: czterech tych Polaków tam spało... w tym dómie... nie... wie $e^{n}$ z myśmy tam nie mieli innej roboty wi $^{n} \mathrm{c}$ żeśmy skórki pościongali...

PoC: no... bo tam była zaroz rzeźnia... tam bili świnie... i tam mówili oberża... albo tag nawyt pisało na tym dómie... ja nie wim...

Obydwa poświadczenia ( $w$ domie / $w$ dómie) pochodzą od osób starszych, które dziś już w większości nie żyją. Fakt ten przesądza o uznaniu formy $w$ domie za wycofującą się z użycia (a być może już zanikłą). Dla porządku dodam, że nie odnotowano jej w materiałach $\mathrm{z}$ pozostałych regionów, choć tam także w latach 70. i 80. XX w. zapisywana była rzadko.

Forma $w$ domu: obecnie ogólnopolska, również w latach 70. i 80. XX w. rejestrowano ją w większości gwar polskich. „Eksploratorzy AJKLW notowali w dom- $u$ prawie na całym badanym obszarze, w wielu punktach jako formę jedyną - przede wszystkim na terenach wschodnich, ale i też w centralnej Wielkopolsce" (KomAJKLW-VIII, 57).

Współcześnie jest to forma dominująca i prawie wyłączna w języku mieszkańców większości badanych miejscowości. Interesujących informacji na temat form $w$ domu / $w$ domie dostarcza wspomniany już artykuł H. Karaś $(2018$, 91), w którym badaczka przytacza dane liczbowe z Narodowego Korpusu Języka Polskiego dotyczące częstotliwości występowania tych form. Zdecydowana przewaga formy $w$ domu nad formą $w$ domie (przenikającą do polszczyzny potocznej) skłoniła badaczkę do wyciągnięcia wniosku, że ,[f]orma analogiczna $w$ domie nie przenika do polszczyzny ogólnej” (Karaś 2018, 92) oraz - odnośnie do zachowania formy $w$ domie na Kresach, a wypierania jej z systemu polszczyzny ogólnej - że ,jest to przejaw tendencji ogólnopolskiej, ale zahamowanej w języku ogólnym, innowacja, która zachowała się na peryferiach obszaru polszczyzny także w odmianie kulturalnej, podczas gdy w centrum (na terytorium współczesnej Polski) pozostała tylko w gwarach. Stąd zasadne może być określanie tej innowacji okresu średniopolskiego, która dłużej utrzymywała się na Kresach w dialekcie kresowym, mianem archaizmu peryferycznego, podczas gdy w polszczyźnie ogólnej stała się już tylko innowacją błędną" (Karaś 2018, 92).

Forma doma: ,przysłówek pełniący funkcję okolicznika miejsca. Forma już prasłowiańska. (...) funkcjonowała w polszczyźnie po wiek XVIII, a jej użycia XIX-wieczne są raczej świadomymi archaizmami stylistycznymi (zob. W. Cyran, Przysłówki polskie, Łódź 1967, s. 181)" (KomAJKLW-VIII, 57). Następnie autor komentarza dodaje, że „[w] materiałach AJKLW forma doma jest zaświadczona z Wielkopolski południowej 
(aż po miejscowości przy Prośnie), zachodniej i północnej” (KomAJKLW-VIII, 57-58). Formę tę, niemalże w całej Polsce, odnotował SGP; także jako ogólnogwarowe podaje formy doma, w doma Maty słownik gwar polskich (MSGP).

Badania współczesne ujawniły tę formę dotychczas wyłącznie w Bukówcu Górnym (informatorzy: MaF - mężczyzna ur. 1922 r., SwS - kobieta ur. 1922 r., SzA - kobieta ur. 1923 r., SlJ - kobieta ur. 1923 r.):

MaF: jeszczy takie powiedzynie buło... a... haróma (!) ja na polu bańka dóma... musiat taki wypadek być... a... haróma... nó tam nie byde klón... to... ja na polu a bańka dóma...

SzA: a on mówi... musi bydź usuninty... tyn zóm ${ }^{m}$... no ja... dobrze... zóm $b$ daam usuno ́́c... jużym sie nie przyznaa dóma... po obiedzie do kopca... a wieczorem na wesele pod okno paczé́...

SwS: jak dziecko nie buło ochrzczóne... nie... to nie buło wolno z nim wyjachać... żeby na ulice aby dzieś... dziecko musiao bydź dóma...

SlJ: a mon ż przyszed... powiado... tydzień powiado... idź do banku po pinióndze... tam dwaeście tysiy cy jakoś... buło pado... dóma nóm sie pinióndz... tam coś chciot kupić... czy ón myślot ze to bydóm pinióndze na jego pogrzeb...

Forma $w$ doma: ,przyimkowa konstrukcja powstała zapewne wskutek kontaminacji form doma i $w$ domu. (...) SStp II, s. 129, rejestruje jedno jej poświadczenie z drugiej połowy XV w. Eksploratorzy AJKLW notowali wyrażenie $w$ doma przede wszystkim w południowej części badanego obszaru (zob. mapę), ponadto koło Szamotuł, Wągrowca i Chodzieży" (KomAJKLW-VIII, 58). Formę tę notuje SGP w regionach południowych Polski, a także w Wielkopolsce i na Krajnie.

Współcześnie nie udało się zarejestrować tej formy w badanych wsiach. Natomiast dla skonfrontowania danych AJKLW z północy regionu, materiał współczesny jest zbyt rozproszony.

Analiza dotychczas pozyskanych poświadczeń terenowych, wykazała wycofujący się charakter badanych form fleksyjnych rzeczownika dom. Już w latach 70. i 80. XX w. dominującą była jedna $\mathrm{z}$ czterech form miejscownika liczby pojedynczej. Od tego czasu zyskała ona jeszcze silniejszą przewagę, gdyż nie wszystkie formy wcześniej notowane przetrwały do dziś. Dla innych form udało się potwierdzić stan z drugiej połowy XX w., choć dotyczy to mowy utrwalonej na początku XXI w. (informatorzy ci obecnie już nie żyją). Uogólniając i podsumowując powyższe analizy stwierdzam, że formy miejscownika liczby pojedynczej wyrazu dom - inne niż $w$ domu - należy uznać współcześnie za wycofujące się z zasobu językowego mieszkańców zbadanych miejscowości.

\section{Literatura}

AJKLW-VIII, Atlas języka i kultury ludowej Wielkopolski, tom VIII: DOM - ZAGRODA, red. Z. Sobierajski, cz. 1: Mapy 656-701, Poznań 1994.

Górnowicz H., Dialekt malborski, Gdańsk 1967.

Karaś H., Formy oboczne miejscownika liczby pojedynczej (w) domu - (w) domie w gwarach polskich na Litwie, „Gwary Dziś”, nr 10, 2018, s. 79-97. 
KomAJKLW-VIII, Atlas języka i kultury ludowej Wielkopolski, tom VIII: DOM - ZAGRODA, red. Z. Sobierajski, cz. 2: Wykazy i komentarze do map 656-701, Poznań 1994.

Małecki M., Nitsch K., Atlas językowy polskiego Podkarpacia, Kraków 1934.

MSGP, Mały słownik gwar polskich, pod red. J. Wronicz, Kraków 2010.

SGP, Stownik gwar polskich PAN, t. VI, z. 1 (16), pod kier. J. Okoniowej, Kraków 2001.

Skoczylas-Stawska H., Zróżnicowanie form fleksyjnych wyrazu dom na pograniczu wielkopolsko-ślasko-matopolskim w województwie kaliskim, [w:] Viro Doctissimo Optime Merito. Prace ofiarowane Profesorowi Zenonowi Sobierajskiemu w 80. rocznicę urodzin, Poznań 1999, s. 166-176.

SStp, Słownik staropolski, t. II, pod red. S. Urbańczyka, Wrocław 1956.

Tokarski J., Gwara Serpelic. Fonetyka. Fleksja, Wrocław-Warszawa-Kraków 1964. 